\title{
Tecnología escáner láser aplicada al estudio del patrimonio cultural edificado de México
}

\author{
Ángel Mora Flores
}

$\Lambda$ partir del mes de mayo del año 2009, el Instituto Nacional de Antropología e Historia (INAH), a través de la Coordinación Nacional de Monumentos Históricos $(\mathrm{CNMH})$, instrumentó la tecnología escáner láser para fortalecer el conocimiento científico y tecnológico en materia de bienes culturales $y$, de acuerdo con este fin, formar una base de datos con modelos digitales de los monumentos históricos y arqueológicos emblemáticos del país. Se trata de una tecnología de postrema generación -cuyas primeras aplicaciones se hicieron en la industria petrolífera- que en los últimos años ha simplificado su manejo y portabilidad. Ponerla en uso hoy para el estudio y salvaguardia del patrimonio edificado constituye una labor institucional sin precedentes.

Con la tecnología láser se tiene, con exactitud y precisión milimétrica, la construcción visual de las estructuras patrimoniales. Esto se realiza con base en millones de puntos láser que se ubican de forma espacial en coordenadas $X, Y$ y $Z$. El haz de luz con el que se producen las imágenes, al ser de baja intensidad, no daña la estructura de los monumentos ni sus materiales. En su capacidad máxima, el escáner registra hasta 50000 puntos por segundo, que se obtienen de manera superficial; los datos se envían a una computadora para su procesamiento, lo que permite crear un solo modelo tridimensional, conformado por una serie de levantamientos, que ofrece a los especialistas un instrumento de vanguardia para determinar acciones que preserven físicamente los sitios históricos.

El INAH tuvo el primer contacto con esta tecnología en 2007, mediante el Centro Dipartimentale per lo Sviluppo di Procedure Automatiche Integrate per il Restauro dei Monumenti (DIAPREM), de la Facultad de Arquitectura de Ferrara, Italia, para realizar dos levantamientos en México: el Monolito de Tlaltecuhtli, hallado en el predio de lo que fue la Casa de las Ajaracas, en el Centro Histórico de la Ciudad de México ( $\mathrm{CHCM}$ ), y en el Bosque de Chapultepec de la misma ciudad, los Baños de Moctezuma.

El proyecto INAH se cristalizó en el año 2008, en colaboración con el Instituto de Restauración del Patrimonio (IRP) de la Universidad Politécnica de Valencia, España, mediante el Proyecto de Cooperación al Desarrollo titulado "Implementación de nuevos métodos de documentación y registro fotogramétrico digital para la protección y puesta en valor del patrimonio monumental mexicano". Dos catedráticos de la Politécnica capacitaron a un grupo de técnicos pertenecientes al INAH en el manejo de la tecnología láser. Posteriormente, durante tres visitas, establecieron pautas para dar conformación y seguimiento a un laboratorio con sede México, al cual se le ha denominado Laboratorio 


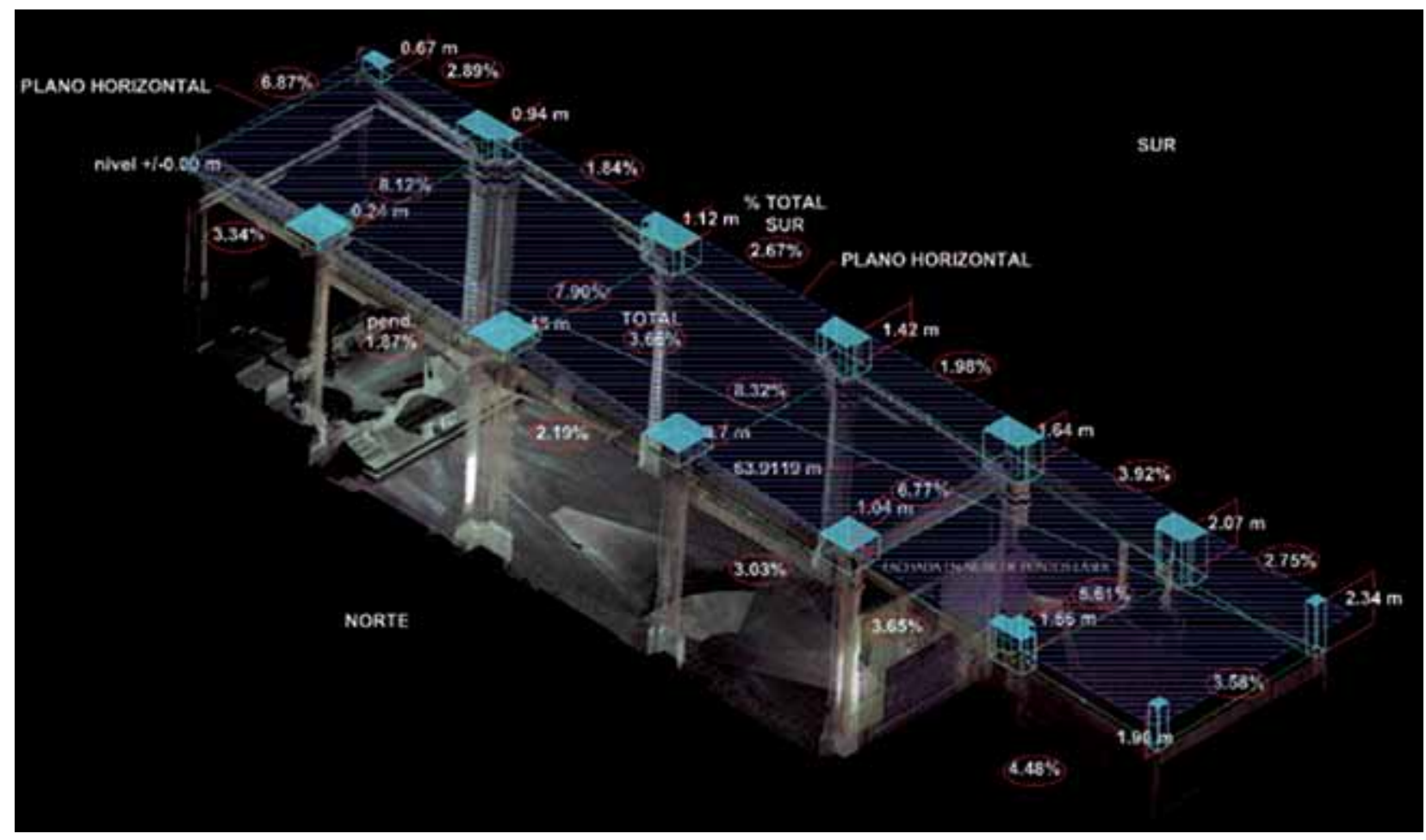

FIGURA 1. Análisis estructural del Templo de la Concepción a partir del levantamiento con tecnología escáner láser. Sobre la representación del cornisamento interior que no ha sido intervenido, se analizó que los porcentajes de inclinación van de 1.42 a 3.92 . Inmueble ubicado en la calle Belisario Domínguez, casi esquina con Eje Central, en el barrio de Cuepopan, al poniente del Centro Histórico de la Ciudad de México, 2009. (Cortesía: LIAD, CNMH-INAH).

de Imagen y Análisis Dimensional (LIAD-CNMH). Éste tiene como objetivo realizar los levantamientos en campo y procesar la información obtenida con el escáner. Mediante procedimientos de gabinete, con la información digital registrada se generan planimetrías, altimetrías, planos topográficos, modelos digitales, con la posibilidad de imprimirlos por medio de estereolitografía (impresión tridimensional a escala). El pragmatismo de los técnicos especializados en el manejo de la información obtenida ha brindado mayor utilidad a las nubes de puntos láser; muestra de esto son los recorridos y la incorporación de puntos a escenarios, ambos virtuales, conservando su mensurabilidad.

A la fecha se han realizado 22 levantamientos parciales en nubes de puntos láser, entre los que destaca el del edificio sede de la CNMH, que sirvió como ejemplo para realizar el procedimiento de capacitación. Como resultado, se cuenta con los planos arquitectónicos del inmueble.

La Plaza Seminario-Manuel Gamio, ubicada al oriente de la Catedral Metropolitana, fue el primer levantamiento que realizó de manera independiente el personal del LIAD. La información obtenida con el escáner se utiliza para el proyecto de lo que será el vestíbulo de acceso a la Zona Arqueológica de Templo Mayor. En tres ocasiones se documentó a detalle la estratigrafía de la excavación, y quedan pendientes por documentar las próximas etapas.
El levantamiento de las cuatro fachadas de Palacio Nacional requirió 26 días de levantamiento y 137 posiciones con el escáner, para obtener a detalle las 4 fachadas, así como 4 meses de trabajo de gabinete, para registrar las diversas nubes de puntos láser obtenidas y el dibujo arquitectónico a detalle de este emblemático monumento.

El registro de las tres arquerías monumentales del Acueducto del Padre Tembleque, la principal ubicada en la localidad de Santiago Tepeyahualco, municipio de Zempoala, Hidalgo, y Nopaltepec, Estado de México, permitió además medir con precisión su longitud: 904.68 m, así como su altura máxima: 37.95 metros.

Los templos de la Santísima Trinidad, la Concepción, Loreto y el claustro del Ex Convento de la Merced, en el $\mathrm{CHCM}$, se escanearon para realizar análisis de niveles, en diferentes elementos y espacios arquitectónicos, y de verticalidad, en retablos y contrafuertes. Estos análisis, llevados a cabo a partir de los puntos láser obtenidos e interpretados por software comercial asistido por CAD, permiten elaborar un dictamen en tiempos reducidos.

El Templo y Antiguo Convento Franciscano de Santa Ana, en Tzintzuntzan, Michoacán, es uno de los levantamientos con mayor avance, ya que se han cuantificado 127 escaneos que se han registrado en un solo modelo tridimensional, lo que ha hecho posible generar en su totalidad las planimetrías y altimetrías para el proyecto de intervención del conjunto conventual. 


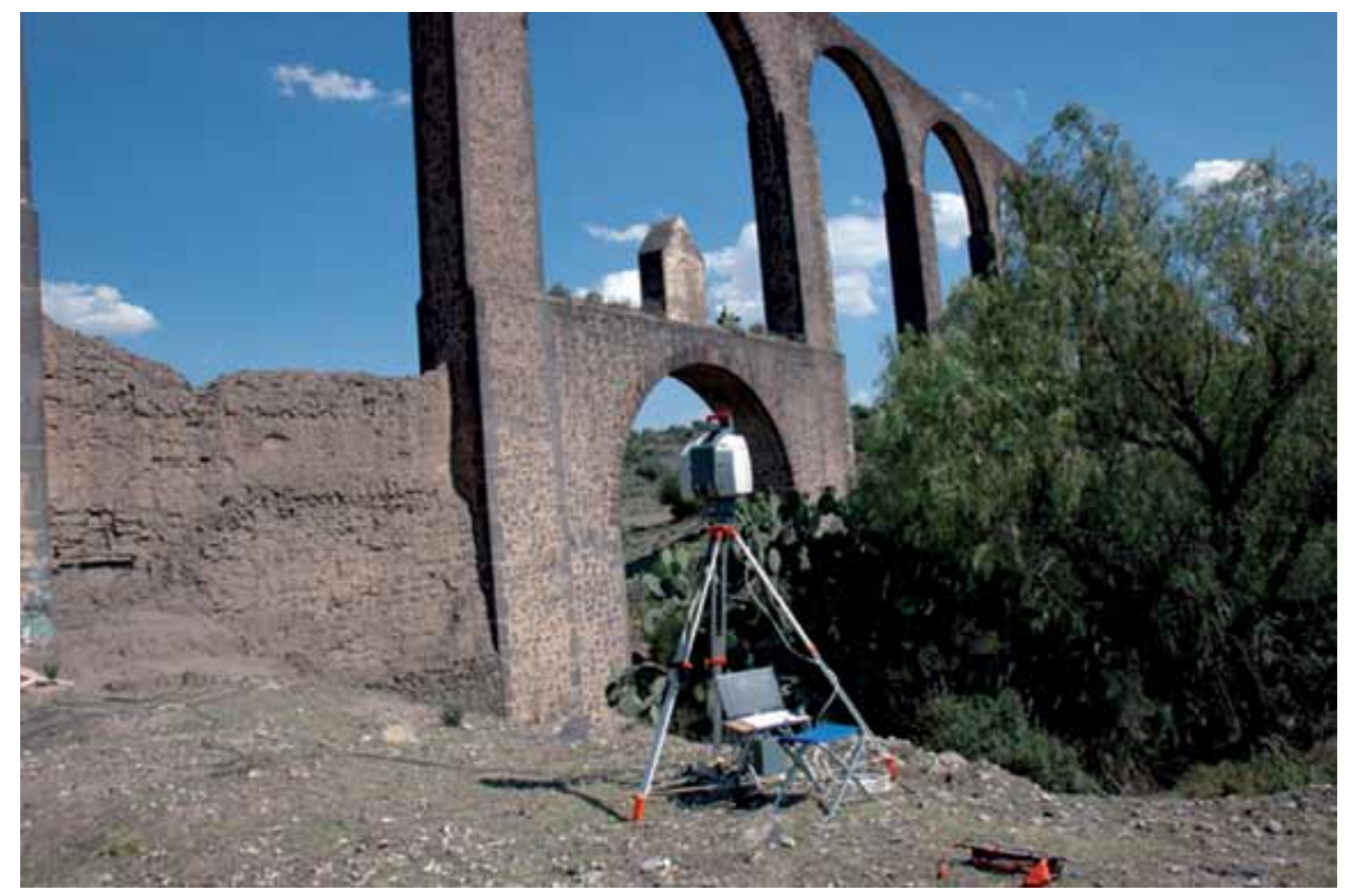

FIGURA 2. Trabajo de levantamiento con el escáner láser de la arquería monumental del Acueducto del Padre Tembleque, en la sección de la Barranca de Tepeyahualco, municipio de Zempoala, Hidalgo, y Nopaltepec, Estado de México, 2010. (Cortesía: LIAD, CNMH-INAH).

El levantamiento, con esta tecnología, de la Fortaleza de San Juan de Ulúa, en el Puerto de Veracruz, tiene $60 \%$ de avance. Hoy en día, esta información se utiliza para apoyar las decisiones técnicas del proyecto integral de intervención de la fortaleza. Como parte del aprovechamiento de los datos obtenidos en campo, que han sido y siguen siendo consultados en gabinete para conseguir diversos análisis métricos, el trabajo de los arquitectos del INAH que supervisan la ejecución de obra en el fuerte se facilita de forma significativa.

Asimismo, se han realizado diversos levantamientos en zonas arqueológicas para documentar estructuras y apoyar estudios especializados por ejemplo: Tlatelolco; el Templo de Quetzalcoatl, en Teotihuacan (donde se ha documentado de forma parcial el túnel hallado, que se registrará en su totalidad con esta tecnología) y la sección de La Ventilla, al sur de la misma zona arqueológica; en las Yácatas, Tzintzuntzan, Michoacán; El Castillo y Juego de Pelota de la Zona Arqueológica de Chichen Itzá, y en fechas recientes, algunas columnas de la Zona Arqueológica del Tajín.

Es así como el Laboratorio de Imagen y Análisis Dimensional de la CNMH construye una base de datos de modelos tridimensionales para garantizar a las generaciones futuras información precisa para la recuperación y la conservación del patrimonio arquitectónico.

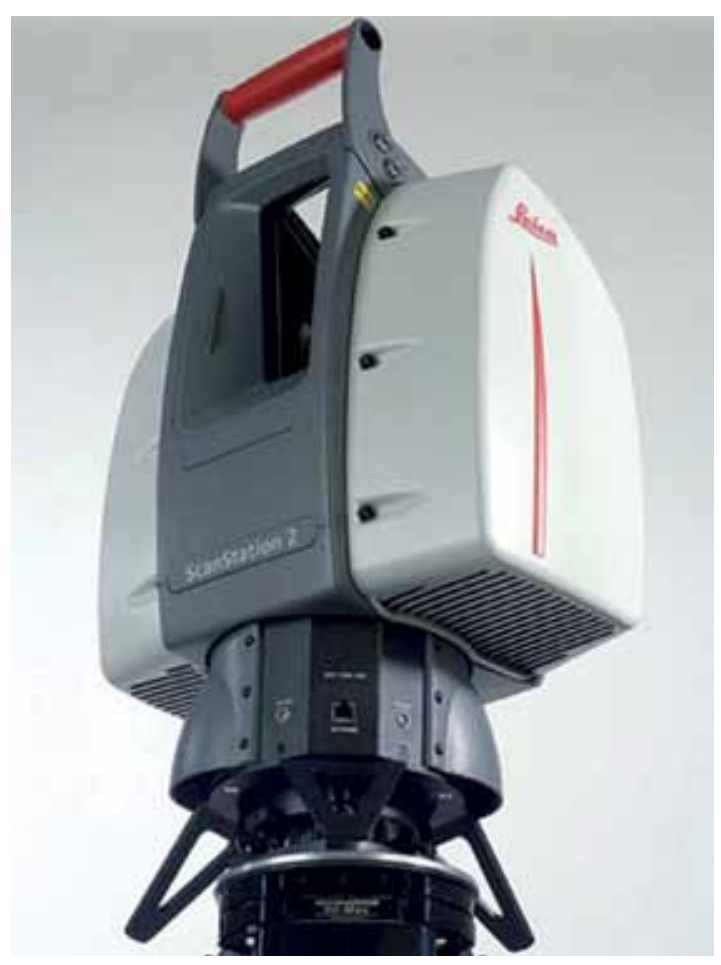

FIGURA 3. Equipo empleado por el LIAD, CNMH-INAH: Leica ScanStation 2. Campo de visión horizontal 360 y vertical 270. Formación de 111 imágenes digitales con rectificado espacial. Alcance de $300 \mathrm{~m}$ de reflectividad. Margen de error: 2 mm. (Cortesía: LIAD, CNMH-INAH). 


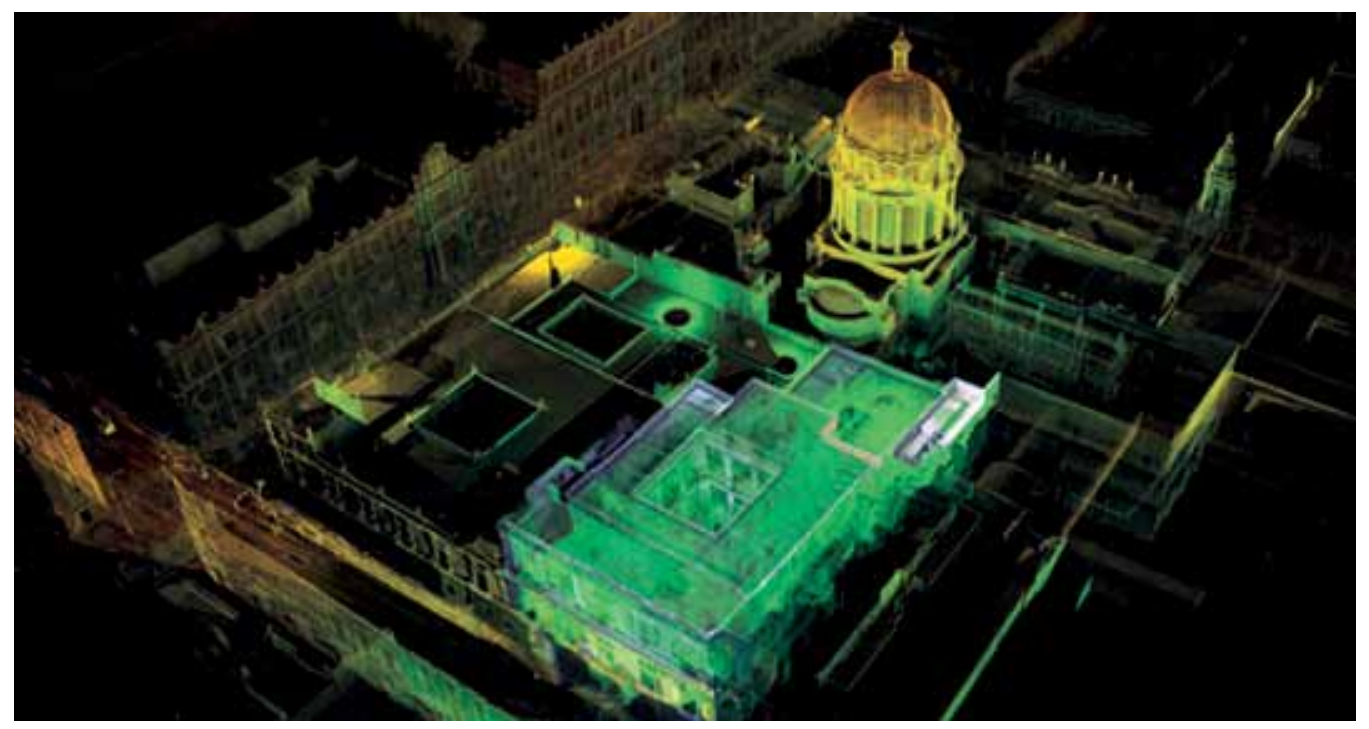

FIGURA 4. Imagen contextual en nube de puntos láser del edificio de la Coordinación Nacional de Monumentos Históricos, ubicado en la calle Correo Mayor 11, Centro Histórico de la ciudad de México. Se observan de forma parcial la fachada norte del Museo Nacional de las Culturas y el Palacio Nacional, así como la cúpula del Ex Templo y Convento de Santa Teresa la Antigua, 2010. (Cortesía: LIAD, CNMH-INAH).

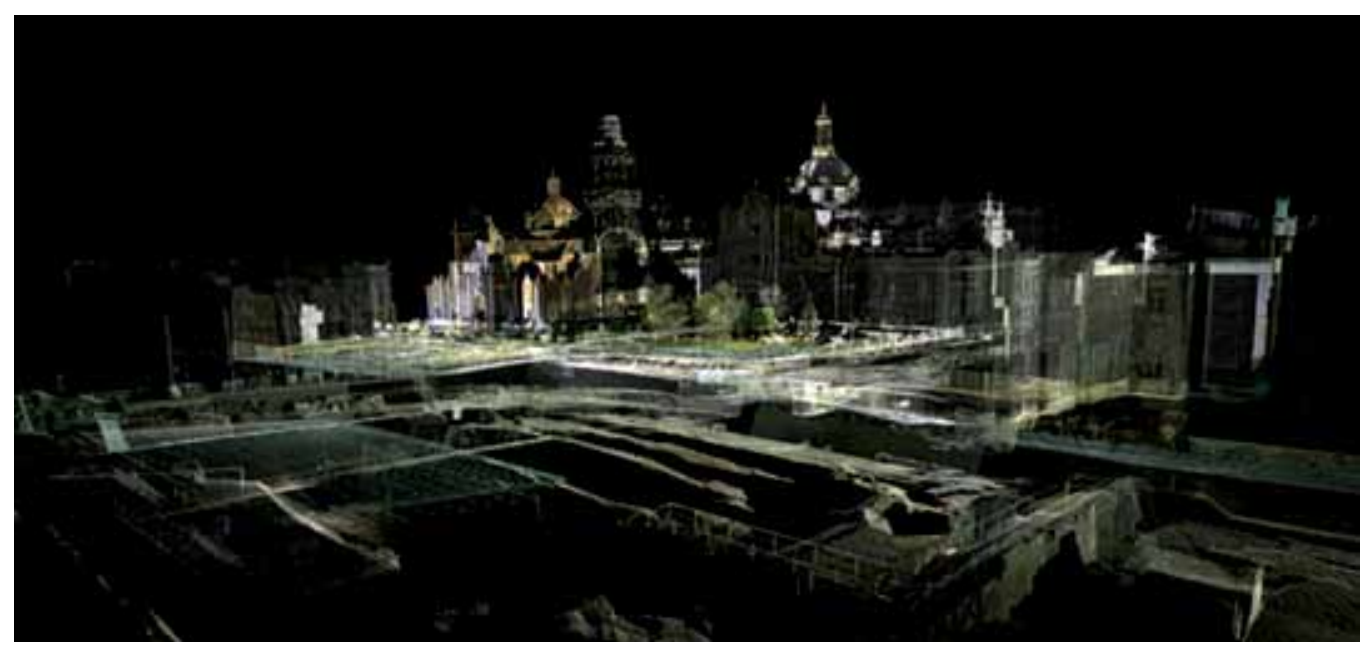

FIGURA 5. Imagen contextual en nube de puntos láser del Centro Histórico de la ciudad de México. En primer plano se observa de forma parcial la Zona Arqueológica de Templo Mayor y, al fondo, la Plaza Seminario-Manuel Gamio; fachada y atrio oriente de la Catedral Metropolitana, 2009. (Cortesía: LIAD, CNMH-INAH).

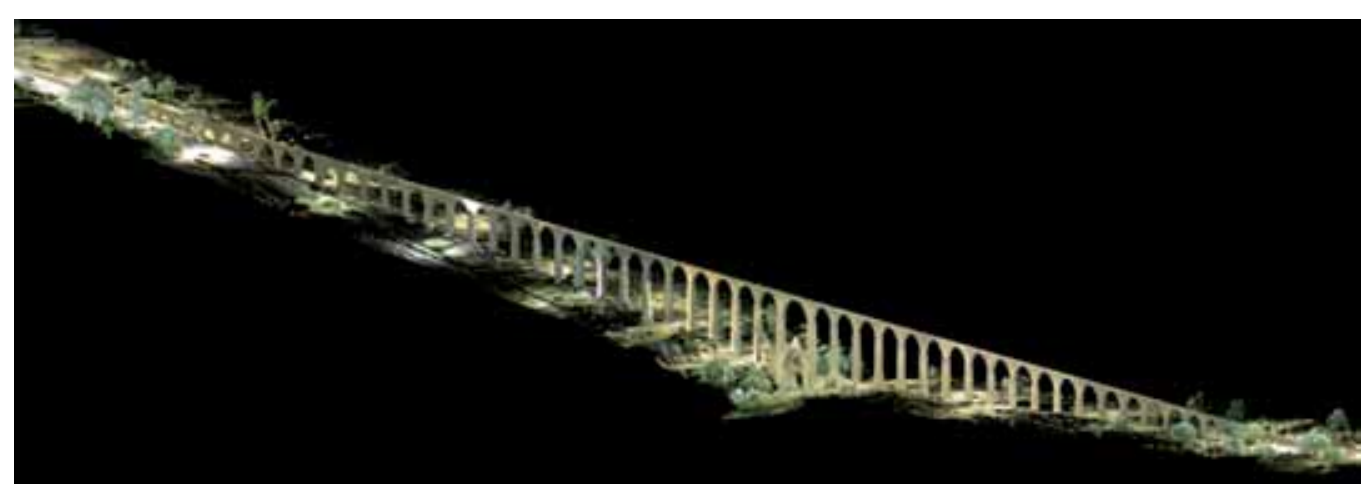

FIGURA 6. Imagen en nube de puntos láser con fotografía de la arcada monumental del Acueducto del Padre Tembleque, en la Barranca de Tepeyahualco, 2010. (Cortesía: LIAD, CNMH-INAH). 